\title{
Na superficie lisa da história: a imprensa e as formas clandestinas de informação
}

\section{On the smooth surface of history: the press and clandestine forms of information}

\author{
Ramsés Albertoni Barbosa ${ }^{1}$ \\ Christina Ferraz Musse ${ }^{2}$
}

Resumo: O artigo investiga as estratégias utilizadas pelos presos políticos ligados ao Grupo Colina, detidos na Penitenciária de Linhares, em Juiz de Fora, para denunciarem os crimes cometidos pelos militares e resistirem ao regime ditatorial, no Brasil, durante as décadas de 1960 e 1970. A reconstrução histórica foi possivel por meio do arquivo de documentos oficiais que comprovam o que se tentou silenciar. Dessa forma, a análise procurou compreender as contradições desses documentos que refletem as atividades que lhes deram origem, pois foram produzidos na vigência de regimes de exceção. A pesquisa se articula em duas frentes complementares, História e Comunicação, cujas "afinidades eletivas" concernem à reflexão acerca das instâncias de interlocução, aos limites e às possibilidades do diálogo entre duas epistemologias.

Palavras-chave: arquivos; ditadura; presos políticos; história; comunicação.

Abstract: This paper investigates the strategies used by political prisoners linked to the Colina Group, detained in Linhares Penitentiary in Juiz de Fora, to denounce crimes committed by the military and resist the dictatorial regime in Brazil during the 1960s and 1970s. The historical reconstruction was possible through the archive of official documents that prove what was tried to silence. Thus, the analysis sought to understand the contradictions of these documents

1 Universidade Federal de Juiz de Fora (UFJF). Juiz de Fora, MG, Brasil. https://orcid.org/0000-0002-5852-9105 E-mail: ramses.albertoni@ich.ufff.br

2 Universidade Federal de Juiz de Fora (UFJF). Juiz de Fora, MG, Brasil. https://orcid.org/0000-0002-3107-3734 E-mail: cferrazmusse@gmail.com 
460 NA SUPERFÍCIE LISA DA HISTÓRIA

that reflect the activities that gave rise to them, since they were produced under exceptional regimes. The research is articulated in two complementary fronts, History and Communication, whose "elective affinities" concern the reflection about the instances of interlocution, the limits and possibilities of the dialogue between two epistemologies.

Keywords: archives; dictatorship; political prisoners; history; communication. 


\section{Os rastros discursivos}

Durante as décadas de 1960 e 1970, em Juiz de Fora, na vigência da ditadura civil-militar de 1964, alguns presos políticos, ligados ao Grupo Colina e detidos na Penitenciária de Linhares, denunciaram os crimes cometidos pelos militares e resistiram ao regime ditatorial, todavia, suas ações raramente apareceram na imprensa juiz-forana. Dessa maneira, pode-se refletir, conforme Barbosa (2013), que os anos 1960 foram marcados por processos em que as relações de poder atravessaram os meios de comunicação. Analisar os rastros discursivos do dito e do não-dito é um aspecto importante na formulação do sentido do relato, pois remete à temporalidade do acontecimento; contudo, para que se compreenda os embates sociais travados no campo da memória é fundamental que se evite cair em generalizações, estigmatizando as interpretações, já que o passado é sempre conflituoso e fragmentário. Dessa forma, a partir da reconstrução de algumas narrativas preteridas, a pesquisa encontrou registros de documentos que comprovam a resistência à ditadura civil-militar de 1964 e o silenciamento da imprensa juiz-forana, porquanto algumas dessas narrativas se entranharam pelas frestas dos discursos hegemônicos e quase escaparam ao seu controle.

$\mathrm{O}$ acesso aos acontecimentos em questão se deu a partir dos arquivos da própria repressão; não obstante, se os arquivos são instituições de memória cultural, igualmente o são lugares de memória investidos de uma aura simbólica que ultrapassa sua mera aparência material e sua funcionalidade, cujos documentos refletem as atividades que lhes deram origem; portanto, é preciso compreender e analisar suas contradições, seu velamento e seu desvelamento, pois foram produzidos na vigência de regimes de exceção, cuja hipertrofia documental constitui uma de suas características, fraudando as práticas funcionais do Estado, porquanto suas práticas de vigilância e controle agenciam um minucioso trabalho de documentação.

Ao analisarmos os poderes discursivos, pondera-se que não se pode falar de tudo em qualquer conjuntura, pois não se tem o direito de dizer tudo, pois a "vontade de verdade" é, conforme Foucault (2007), 
conduzida pela forma como o saber é aplicado em nossa sociedade, como ele é valorizado e atribuído, exercendo poder de coerção sobre outros discursos, já que discurso e poder se imbricam. De acordo com o autor, a produção de discursos, em qualquer sociedade, é controlada com o desígnio de conjurar-lhe os poderes e os perigos, enfraquecendo a eficácia de eventos incontroláveis, no intuito de ocultar as forças que materializam a constituição social. Portanto,

Teria então chegado o momento de considerar esses fatos de discurso, não mais simplesmente sob seu aspecto linguístico, mas, de certa forma e aqui me inspiro nas pesquisas realizadas pelos anglo-americanos como jogos (games), jogos estratégicos, de ação e de reação, de pergunta e de resposta, de dominação e de esquiva, como também de luta. O discurso é esse conjunto regular de fatos linguísticos em determinado nível, e polêmicos e estratégicos em outro (FOUCAULT, 2003, p. 9).

Dessa forma, para que a vontade de verdade seja exercida satisfatoriamente, são utilizados procedimentos externos e internos ao discurso. Enquanto os procedimentos externos ao discurso limitam a produção de discursos, interditando a palavra, e definindo o que pode ser dito/ não-dito em cada circunstância, através do "tabu do objeto" e do direito privilegiado ou exclusivo de quem fala; os procedimentos internos ao discurso possuem a função de classificar, ordenar e ditar sua distribuição.

Logo, o discurso não reflete apenas o controle do poder, mas é, igualmente, o próprio poder, o que exige dos indivíduos um questionamento sobre a busca de verdade, devendo-se atribuir ao discurso o caráter de acontecimento, que se efetiva sempre no âmbito da materialidade, pois possui seu lugar e tempo bem demarcados. Ao empreendermos a perquirição dos sentidos do silêncio como algo que significa e que se distingue do implícito, que precisa do "dito" para colocar-se sob o sentido, será possível pensar o silêncio como agente da censura que diz respeito ao que não pode ser enunciado em determinadas circunstâncias.

Os Inquéritos Policiais Militares (IPMs), por nós analisados, se constroem como narrativas intertextuais, pois o que constitui a intertextualidade é a relação de co-presença entre dois ou mais textos. A origem 
destas formas, no final do século XIX, ocorreu concomitantemente com a formação de certo número de controles políticos e sociais. Por conseguinte, o IPM, conforme Fronza (2017), possibilita ao Ministério Público Militar (MPM) apreciar a prática do fato delituoso com todas as suas circunstâncias, e refere-se à apuração sumária do fato e de sua autoria que, nos termos legais, configure crime militar, possuindo caráter de instrução provisória, cuja finalidade é a de fornecer elementos para a propositura da ação penal; todavia, as perícias, os exames e as avaliações são instrutórias dessa ação e devem observar as formalidades legais quanto à sua realização, cujo encarregado do inquérito deve se restringir à apuração completa dos fatos definidos na portaria de sua designação.

O inquérito, conforme Foucault (2003), é uma forma de verdade definida por meio das práticas judiciária e penal e o seu estudo demonstra como as práticas sociais engendram domínios de saber que além de construírem novos objetos, conceitos e técnicas, engendram novas formas de sujeitos e de sujeitos de conhecimento que possuem uma história na sua relação com o objeto, haja vista que a própria verdade possui uma história. O autor aponta que existem duas histórias da verdade, a história interna da verdade, que se corrige por meio da autorregulação, e a história externa da verdade, que se forma em outros lugares de saber por meio de certo número de regras definidas, como as práticas judiciária e penal, porquanto,

As práticas judiciárias - a maneira pela qual, entre os homens, se arbitram os danos e as responsabilidades, o modo pelo qual, na história do Ocidente, se concebeu e se definiu a maneira como os homens podiam ser julgados em função dos erros que haviam cometido, a maneira como se impôs a determinados indivíduos a reparação de algumas de suas ações e a punição de outras, todas essas regras ou, se quiserem, todas essas práticas regulares, é claro, mas também modificadas sem cessar através da história - me parecem uma das formas pelas quais nossa sociedade definiu tipos de subjetividade, formas de saber e, por conseguinte, relações entre o homem e a verdade que merecem ser estudadas (FOUCAULT, 2003, p. 11). 
O inquérito, desse modo, é a forma mais característica da verdade em nossa sociedade, cujo surgimento se dá na Idade Média como forma de investigação da verdade no cerne da ordem jurídica.

Portanto, ao se adentrar nos arquivos da "memória institucional" percebe-se que sua configuração evidencia uma pluralidade de memórias que se transformam e se sucedem à medida que novas informações vêm a público, subsidiando mudanças no conhecimento até então existente sobre o regime ditatorial, pois saber sobre o conhecimento é ter consciência que sua origem se encontra nas relações de poder e na maneira como os homens querem exercer, uns sobre os outros, relações de poder (FOUCAULT, 2003). Dessa forma, a investigação e a análise de todo o material recolhido durante a pesquisa procura identificar, consequentemente, as estratégias discursivas utilizadas igualmente pela imprensa e pelas produções clandestinas para narrar os acontecimentos que dizem respeito à cidade de Juiz de Fora, interpretando quais foram os critérios utilizados para narrar ou ocultar os fatos, pois analisar o papel da censura durante o período da ditadura civil-militar é procurar estabelecer um diálogo com a memória construída acerca da ingerência sobre a imprensa e da criminalização dos que se opunham ao poder do Estado. Por conseguinte, será necessário mapear as relações sociais, suas reconfigurações e suas diferentes formas de produção, avaliando seus impactos na produção, circulação e consumo de notícias, estabelecendo os fatos e agenciando a construção de um sentido do passado no presente, garantindo a problematização e a inteligibilidade das representações do passado que perduram na memória coletiva e que ajudaram a consolidar certas narrativas em detrimento de outras.

O manuseio dos documentos desses arquivos institucionais requer cuidados metodológicos que considerem a natureza do funcionamento do regime de exceção, os processos de mediação utilizados e, mormente, suas condições de produção, porquanto, nesses regimes a produção documental reproduz as práticas delituosas, cujo escopo é criar provas contra seus inimigos e, concomitantemente, de se autodefender das acusações que lhe são impingidas. Dessa forma, toda essa documentação 
deve ser lida com a marca da suspeita, haja vista que foi produzida em situações marcadas pela violência de situações-limite.

É preciso destacar que o artigo se articula em duas frentes complementares, História e Comunicação, cujas "afinidades eletivas" dizem respeito à reflexão acerca das instâncias de interlocução, aos limites e às possibilidades do diálogo entre duas epistemologias, sendo tomadas, em sentido estrito, como expressão de configurações culturais. Por conseguinte, as afinidades eletivas entre História e Comunicação são o resultado de um arranjo único e de uma inter-relação das partes, o que constitui uma nova entidade que revela as (des)continuidades entre essas duas formas de operacionalização e de compreensão da realidade social. Logo, esse conceito abre possibilidades para a compreensão de realidades e de relações complexas, expandindo o campo para a superação de um reducionismo estrito que apaga as nuances dos significados atribuídos às relações sociais estabelecidas.

Dessa forma, ao construirmos o percurso teórico a partir dos arquivos da memória institucional da ditadura civil-militar de 1964 no Brasil, os conceitos de Comunicação, História, verdade e poder estarão conjugados com a noção de arquivo que não é apenas o registro dos enunciados, mas igualmente sua ordenação hierárquica em várias séries discursivas. Consequentemente, é mister cometer a leitura crítica desses arquivos, descobrindo suas lacunas, rasuras e esquecimentos, propondo, inclusive, a desconstrução desse conceito que se arvora como algo estático e fixo em sua ontologia, de tal modo que se transforma, em sua materialidade, num conjunto de documentos estabelecidos como a positividade da verdade da experiência histórica (DERRIDA, 2001). Ao resgatar alguns conceitos foucaultianos, Derrida (2001) perfaz uma reinterpretação da versão clássica do arquivo presente no discurso da História, enunciando uma concepção original, considerando o arquivo como algo lacunar, sintomático e descontínuo, perpassado pelo esquecimento.

$\mathrm{O}$ arquivo, por meio do exergo, o espaço, em moedas ou medalhas, destinado à gravação de data ou de inscrição, comete uma "violência arquival”, a violência do poder que coloca e conserva o direito, 
[...] pois todo arquivo [...] é ao mesmo tempo instituidor e conservador. Revolucionário e tradicional. Arquivo eco-nômico neste duplo sentido: guarda, põe em reserva, economiza, mas de modo não natural, isto é, fazendo a lei (nomos) ou fazendo respeitar a lei. Há pouco, como dizíamos, nomológico. Ele tem força de lei, de uma lei que é a da casa (ô̂kos), da casa como lugar, domicílio, família ou instituição (DERRIDA, 2001, p. 17-18).

Empreender a leitura crítica do arquivo e propor sua desconstrução implica, portanto, não somente articular uma nova interpretação do passado e da tradição, mas, principalmente, uma leitura diversa da concepção da história. O arquivo será interpretado como algo lacunar e sintomático, uma descontinuidade perpassada pelo esquecimento e pelo apagamento, já que discurso e poder se imbricam no conceito de arquivo, haja vista que a verdade não se dissocia da singularidade do acontecimento, pois ele é produzido num espaço e num tempo específicos.

Sendo assim, cabe ao pesquisador reconstruir as partes dispersas, historiando sua Herkunft (proveniência) e sua Entstehung (emergência), pois nada existe além da disseminação histórica do acontecimento que se desvia constantemente, pois as forças históricas conflitantes se digladiam no acaso da luta, sendo necessário interpretar as sedimentações escondidas sob o véu do visível. O pesquisador submete, assim, as verdades históricas a uma exegese, procurando desvendar as "estratégias de poder" com pretensão de verdade, já que a própria verdade é um acontecimento. Dessa forma, é preciso elucidar quais são as conexões que podem ser observadas entre os mecanismos de coerção e os elementos de conhecimento (FOUCAULT, 2018).

Por conseguinte, considera-se que toda forma de saber possui uma positividade que não se condiciona à cientificidade e que não pode ser julgada por uma referência que não seja o próprio saber. É necessário especificar, dessa forma, um método de investigação que visa entender a ordem interna que constitui um determinado saber, por isso, a análise arqueológica precisa transitar por diferentes formulações conceituais, 
pertencentes a diferentes saberes, pois a História se dispunha a "memorizar" o passado, transformando-o em documentos

[...] e fazer falarem estes rastros que, por si mesmos, raramente são verbais, ou que dizem em silêncio coisa diversa do que dizem; em nossos dias, a história é o que transforma documentos em monumentos e que desdobra, onde se decifravam rastros deixados pelos homens, onde se tentava reconhecer em profundidade o que tinham sido, uma massa de elementos que devem ser isolados, agrupados, tornados pertinentes, inter-relacionados, organizados em conjuntos. Havia um tempo em que a arqueologia, como disciplina dos monumentos mudos, dos rastros inertes, dos objetos sem contexto e das coisas deixadas pelo passado, se voltava para a história e só tomava sentido pelo restabelecimento de um discurso histórico; que poderíamos dizer, jogando um pouco com as palavras, que a história, em nossos dias, se volta para a arqueologia - para a descrição intrínseca do monumento (FOUCAULT, 2008, p. 8).

A arqueologia foucaultiana é uma maneira de fazer história que considera todas as práticas discursivas a partir do estatuto do acontecimento, pois o que foi dito instaura uma realidade discursiva que permite deslindar como o homem constrói sua própria existência, já que os sujeitos e os objetos não existem a priori, mas são construídos discursivamente sobre o que se fala sobre eles. Enquanto a arqueologia é o método de análise das "discursividades locais", a genealogia é a tática que faz intervir os "saberes dessujeitados" que se desprendem da análise, porquanto foram qualificados como saberes não conceituais e insuficientemente elaborados por uma hierarquia dos saberes (FOUCAULT, 1999). Assim, no momento em que se resgata esses fragmentos de genealogia, eles correm o risco de serem recodificados e recolonizados pelos saberes de poder. Por isso, o pesquisador precisa estar atento à "batalha dos saberes" versus as implicações de poder do discurso científico. Por meio da análise de um conjunto de documentos, é consentido ao pesquisador estabelecer certo número de relações e interpretar todo o material disponível

[...] para apreender por trás dele uma espécie de realidade social ou espiritual que nele se esconderia; seu trabalho consiste em manipular e tratar uma série de documentos homogêneos concernido a um objeto 
particular e a uma época determinada, e são as relações internas ou externas desse corpus de documentos que constituem o resultado do trabalho do historiador (FOUCAULT, 2008, p. 291).

A arqueologia documental estaria voltada, então, para o estudo das interpretações, apropriações, criações e regulações do conhecimento por parte das sociedades em determinados momentos históricos, possibilitando a formação de atos de fala enunciativos ou elocutórios que estariam contidos no interior das formações discursivas orientadas por um regime de verdade.

Dessa maneira, a nossa proposta é analisar os processos jurídico-militares da ditadura civil-militar não apenas em seus traços patentes e ostensivos, mas também nas múltiplas leituras autorizadas pela condição de posterioridade do intérprete. Ao analisarmos a arqueologia e a genealogia dos processos jurídico-militares perpetrados na Auditoria da $4^{\text {a }}$ CJM, podemos sopesar que eles configuram uma prática penal que constrói uma forma da verdade em nossas sociedades, cuja origem pode ser encontrada em uma prática política e administrativa, inclusive, na prática judiciária.

\section{0 manuscrito apreendido}

Em razão do Processo 73/69 ocorreu o interrogatório coletivo de 12 presos políticos ligados ao Grupo Colina detidos na Penitenciária de Linhares, entre os dias 19 e 20 de março de 1970, na sede da $4^{\text {a }}$ CJM, em Juiz de Fora, e que durou 27 horas. A sessão fora presidida pelo juiz-auditor Mauro Seixas Telles com a presença dos juízes militares do Conselho Permanente de Justiça, cujo objeto da acusação desse processo militar, que investigava 20 pessoas no total, refere-se à provocação de guerra subversiva, sabotagem e terrorismo, agrupamento paramilitar, propaganda subversiva, posse ilícita de armamentos, apologia de crime contra a segurança nacional, motim, tentativa de homicídio qualificado e favorecimento real. 
Os presos políticos interrogados foram Ageu Heringer Lisboa, José Raimundo Jardim Alves Pinto, Marco Antônio de Azevedo Meyer, Marcos Antônio Rocha, Pedro Paulo Bretas, Nilo Sérgio Menezes de Macedo, Afonso Celso Lana Leite, Ângelo Pezzuti, Júlio Antônio Bittencourt de Almeida, Maurício Vieira de Paiva, Murilo Pinto da Silva e Irany Campos. Entretanto, esses presos políticos aproveitaram o interrogatório para denunciarem as torturas cometidas pelo sistema ditatorial, além de questionarem o tribunal militar que os interrogava.

Apesar das graves denúncias pronunciadas no tribunal militar, o jornal Diário Mercantil, dois dias depois, em 21 de março de 1970, noticiou o fato de maneira abreviada e ocultou a gravidade dos relatos, feitos pelos detentos, de sevícias, torturas e assassinatos cometidos pelo regime ditatorial, conforme citação a seguir:

Num ambiente de grande tensão, a que se aliou o visível cansaço dos juízes, do promotor Simeão de Faria Filho e dos demais funcionários da justiça, 14 acusados foram ouvidos, e alguns dos depoimentos duraram mais de 3 horas cada um. Segundo informação da Auditoria, são 28 acusados, mas nem todos se encontravam presentes, e outros são apontados como criminosos em outros processos (Conselho Permanente ouviu membros do Grupo "Colina". Diário Mercantil, Juiz de Fora, p. 8, 21 mar. 1970).

No dia 2 de abril de 1970, o $2^{\circ}$ tenente da PM Mariano estava de oficial-de-dia na Penitenciária de Linhares, ocasião em que ocorria a visita aos presos políticos. Os irmãos Ângelo e Murilo receberam a visita de seu pai, Theofredo Pinto da Silva, e alguns parentes. Durante a visita, o sargento Edmundo percebeu que Ângelo portava em sua mão um papel dobrado em quatro partes que passou ao seu pai, no momento do abraço de despedida. O sargento, então, aguardou que as visitas se retirassem do recinto e instruiu o cabo substituto da guarda Iguatemir para que apreendesse o tal papel. Assim, o cabo encaminhou Theofredo à Reserva do Contingente, sala contígua à sala de entrevistas, e entregou o papel apreendido ao sargento Gomes. Esse papel era o jornal clandestino Até Sempre 3. 
O manuscrito Até Sempre 3 consta de uma peça de 11 folhas de papel branco, tipo seda, sem pautas, numeradas de 12 a 24, grampeadas, com capa em papel de cor amarela, manuscritas a caneta esferográfica de carga azul, em caracteres imitativos tipográficos apresentando como título os seguintes dizeres: "Até Sempre 3 - Caderno Especial - Revista Quinzenal: Debates - Fevereiro - Março/1970 - A ditadura no banco dos réus - H. Expect" (PROCESSO 32/70, p. 381). A primeira página desse manuscrito consta de um editorial em que o autor H. Expect acusa a ditadura civil-militar de imperialismo, relatando que durante a sessão de interrogatório coletivo ocorrida em março, houve um clima tenso em que todos os responsáveis pelo julgamento estavam submissos aos "milicos" e que os réus tiveram suas defesas obstruídas desde a Penitenciária de Linhares, local onde lhes foram confiscados os relatos escritos que haviam preparado para entregar no tribunal militar. Nesse editorial se afirma a tentativa de reconstituição dos aspectos mais importantes do interrogatório coletivo, e conclui chamando o tribunal de farsa.

Após a análise do manuscrito Até Sempre 3, foi-nos possível verificar que os interrogados construíram um discurso de conformidade em suas avaliações e julgamentos, porquanto negaram o teor de seus interrogatórios anteriores, formulados sob tortura e coação, além de denunciarem os responsáveis pelas sevícias em diversas instituições e os maus-tratos recebidos na penitenciária. A partir dos autos do Processo 73/69, em que consta os depoimentos referidos no manuscrito Até Sempre 3, foi-nos possível também fazer um cotejamento entre os dois discursos, o oficial e o clandestino, e perceber suas semelhanças com leves diferenças de tom.

O capitão Walter, diretor da Penitenciária de Linhares, só fora informado da apreensão do manuscrito Até Sempre 3, às 19 horas, do mesmo dia, pelo funcionário público estadual Afonso José, e no dia 3 de abril de 1970, comunicou, em caráter reservado, ao general Itiberê, comandante da $4^{\text {a }}$ Região Militar, que, no dia anterior, 2 de abril, fora apreendido, pelo serviço de vigilância externa da penitenciária, um documento com “informações subversivas" (PROCESSO 32/70, p. 10). 
Após o recebimento dessas informações, o general emitiu a Portaria 06/J, em 7 de abril, determinando a instauração, com a possível urgência, do IPM e designou o capitão Verlangieri como encarregado do inquérito. As primeiras ações do capitão fora emitir, em 15 de abril de 1970, um mandado de prisão contra Theofredo e no dia 25 de abril, em virtude da suspeita de existência de outros informes e/ou objetos proibidos em poder dos presos políticos e dos presos comuns, realizar uma diligência na Penitenciária de Linhares em que foi possível caracterizar a continuada atividade delituosa por parte dos detentos. Contudo, com a finalidade de não tumultuar a investigação do Processo 32/70, o capitão resolveu não arrolar indiscriminadamente os documentos e objetos apreendidos, deixando sua interpretação e análise para um outro IPM, mais específico (PROCESSO 32/70, p. 221).

No dia 7 de maio de 1970 fora publicado o Relatório do capitão Verlangieri, indiciando todos os envolvidos do processo, e enviado ao general comandante. Em 15 de maio de 1970, o general Itiberê enviara a Solução do IPM ao juiz-auditor Mauro Seixas Telles que, contudo, no mês seguinte, esclareceu que os denunciados Ângelo e Murilo tiveram a ação penal sustada em virtude de terem sido banidos do território nacional, conforme o AI-13, de 5 de setembro de 1969. Ângelo e Murilo estavam entre os 40 presos políticos trocados pelo embaixador alemão, Ehrenfried Anton Theodor Ludwig von Holleben, sequestrado pela guerrilha urbana, em 11 de junho de 1970, e foram levados à Argélia.

Após várias diligências e apreensões de documentos, o procurador-militar substituto da Auditoria da $4^{\mathrm{a}}$ CJM, Joaquim Simeão de Faria Filho, ofereceu, em 23 de julho de 1970, denúncia contra Theofredo, Ângelo, Murilo e, posteriormente, Ângela Maria Pezzuti, acusada de levar informações para os sobrinhos detidos, e Erwin Rezende Duarte, acusado de propaganda subversiva e apologia de crime contra a segurança nacional (PROCESSO 32/70, p. 232).

Nessa mesma data, o procurador-militar solicitara ao juiz-auditor o exame grafotécnico do manuscrito Até Sempre 3 com relação aos presos políticos Nilo Sérgio Menezes, Délio Fantini, Erwin Rezende Duarte, 
Jorge Batista Filho, Pedro Paulo Bretas e Júlio Antônio Bittencourt de Almeida, para revelar a autoria do manuscrito, cuja culpa recairia sobre Erwin que, entretanto, nega a autoria do manuscrito apreendido, solicitando novo exame grafotécnico, mais rigoroso que o anterior. Contudo, os peritos constatam novamente "perfeita convergência de características gráficas morfo-cinético-estruturais entre os grafismos motivo e padrão ora confrontados, podendo afirmar, categoricamente, a procedência gráfica comum destas peças" (PROCESSO 32/70, p. 382). No entanto, ao final do Processo 32/70, a autoria do manuscrito Até Sempre 3 continuará a ser uma incógnita.

O julgamento final dos acusados, com as absolvições de todos os envolvidos no processo, ocorreu entre os dias 10 e 23 de agosto de 1971, na sede da Auditoria da $4^{\text {a }}$ CJM, na Sala de Sessões. O julgamento de Theofredo, Ângela e Erwin ocorreu no dia 10 de agosto de 1971, em audiência pública. Os membros do Conselho Militar argumentaram que o Processo 32/70 versava a respeito de alguns presos políticos acusados de terrorismo e liderados por Ângelo. Segundo o Conselho, esses presos políticos deram continuidade a atividades "comuno-subversivas" dentro da Penitenciária de Linhares através da "já demais conhecida guerra psicológica adversa”, visando levar ao conhecimento público, de maneira desvirtuada, "uma ideia truncada do que fora um ato processual" (PROCESSO 32/70, p. 501). Por fim, o Conselho Militar concluiu que como o manuscrito Até Sempre 3 não conseguira amealhar a publicidade desejada, o que consumaria o delito, resolveu-se entender que o fato não chegou a ferir a norma penal e, por unanimidade, julgou improcedente a denúncia, reconhecendo que os fatos narrados não chegaram a tipificar delito. Posteriormente, fora extinta a punibilidade de Ângelo nos outros processos militares a que respondia, em razão de seu óbito, ocorrido na França, em 1975. Em 3 de setembro de 1979, oito anos após o encerramento do Processo 32/70, o Conselho Militar decretou extinta a punibilidade de Murilo, em face da Lei n ${ }^{\circ} 6.683 / 79$, a Lei de Anistia. 


\section{0 que resta é o silêncio}

Ao analisar a vasta documentação disponível, foi-nos possível averiguar que a imprensa juiz-forana explorou o fato do golpe civil-militar ter se iniciado em Juiz de Fora, e não obstante todo o seu empenho em defender o golpe civil-militar, se calou diante das atrocidades cometidas pelo regime ditatorial. Dessa forma, conforme Barbosa,

Apesar de termos que considerar que a censura política em momentos de autoritarismo age de forma intermitente, não constante e de maneira diferenciada em relação aos veículos de comunicação, desde o Golpe de 1964 instauraram-se mecanismos diversos para controlar as informações veiculadas. $\mathrm{O}$ argumento frequentemente apresentado para a instituição da censura em todas as dimensões da vida cultural do país coloca em evidência o papel que se atribuía aos meios de comunicação: além de informar, deveriam orientar a população, tutelados pelo Estado. Os conteúdos que poderiam servir de estímulo à oposição dos militares deveriam ser alijados das publicações (BARBOSA, 2013, p. 296-297).

O argumento-padrão utilizado por certa imprensa, para justificar as ações de exceção, é que se vivia um período de "guerra" promovida pelos "terroristas" comunistas.

Com relação à justiça militar, o almirante-de-esquadra Júlio de Sá Bierrenbach, ex-ministro do STM durante a ditadura, comenta que o caso mais complicado que enfrentou foi o do preso político Paulo José de Oliveira Moraes, membro de uma quadrilha de assaltantes de bancos e réu em vários processos. Segundo o militar,

De um modo geral, acredito que esse foi o melhor serviço que prestei à Justiça Militar. [...] Teve ampla repercussão, e, não tenho dúvida, reduziu muito a prática de torturas e sevícias nas delegacias policiais de vários estados do país. [...] Ouvi de vários advogados que nos julgamentos em segunda instância, isto é, no Tribunal, os juízes devem se restringir ao que consta dos Autos. Mesmo depois de assumir o cargo, várias vezes ouvi: "O que não está nos autos não está no mundo”. Esse caso, eu digo que foi um bom serviço porque as polícias aí ficaram... vendo que a gente checava tudo (BIERRENBACH, 2010, p. 4-6). 
O ministro Bierrenbach ficara famoso por respeitar os presos políticos e por agir de forma ética.

Conforme depoimento de Antônio Modesto Silveira, advogado de vários presos políticos que foram julgados em Juiz de Fora, à CMV-JF, existiam dois tipos de juízes na cidade, um, que era visto com muita frequência bêbado, frequentador da zona de prostituição da cidade, e

[...] um juiz aqui chamado Antônio Arruda Marques, era um juiz auditor, muito correto e digno. $[\ldots]$ Pois bem, $[\ldots]$ esse juiz digno de direito, $[\ldots]$ ele simplesmente mandou ofício pro [...] Superior Tribunal Militar, informando o que tinha acontecido e mais, enquanto eles não mandarem a lista legal ele não tem condição ética e nem legal de fazer audiência e disse "Estou com a auditoria fechada até que a lei seja cumprida". [...] O que que acontece, a ditadura se encarrega de cassar os direitos e até a função do juiz (DEPOIMENTOS, 2017, p. 7-9).

Por conseguinte, ao recuperarmos o conteúdo dos processos jurídico-militares, em que são narrados os julgamentos de vários presos políticos e cotejando-os com as notícias divulgadas pela imprensa juiz-forana, observa-se a incapacidade da imprensa em relatar os desmandos das forças repressoras e, em alguns casos, até o apoio explícito.

Em depoimento à CMV-JF, o fotógrafo do jornal Diário Mercantil, Antônio Geraldo Carvalho, vulgo Toninho Carvalho, comenta sobre a rotina de trabalho num período de ditadura:

[...] porque nós, como fotógrafos, a gente é mais uma... quase que uma máquina, né. [...] Então, quantas entrevistas foram feitas comigo lá, eu fui fazer com o repórter lá na Penitenciária de Linhares, quantos julgamentos já fui ali na Praça Antônio Carlos pra fazer, fotografar o julgamento de algum preso político, né. E na Penitenciária de Linhares praticamente metade era preso político, né. Então, assim, tem vários momentos em que eu tive lá na Auditoria de Guerra... da Justiça Militar, e fui impedido de fotografar (DEPOIMENTOS, 2017, p. 2-3).

O jornalista Wilson Cid, correspondente na época, em Juiz de Fora, do jornal O Globo, em depoimento à CMV-JF, menciona que chegou a assistir a alguns julgamentos na Auditoria da $4^{\mathrm{a}} \mathrm{CJM}$ e que presenciou 
algumas situações interessantes, todavia, para nossa surpresa, afirma que não tivera acesso a informações sobre maus-tratos a presos políticos. Segundo ele,

As prisões a gente sabia que havia as prisões, sobretudo quando começaram os julgamentos na Auditoria, porque entrava o promotor denunciando e entrava o advogado fazendo a defesa, e a gente ali, então, ficava sabendo. [...] Mas assim, saber diretamente do preso, fulano está apanhando, fulano foi ser indiciado, na época era complicado. A gente não tinha acesso a esse tipo de informação. [...] Mas lidar com a censura, isso é muito chato, deixa uma marca que você não quer nem saber. A marca mais grave disso tudo é a que criamos uma geração de jornalistas preocupados... na escrita, "segundo disse, fulano de tal declarou", o jornalista às vezes tem medo de assumir a informação. Ele atribui ao outro (DEPOIMENTOS, 2017, p. 4-5).

Fica-nos a impressão que o jornalista ficou gravemente marcado pela censura.

No entanto, o advogado Antônio Modesto corrobora a versão dos presos políticos ao afirmar que ouviu, de seus clientes, vários relatos sobre tortura em Juiz de Fora.

Mas, ah, busquei ouvir pelos clientes meus, não tinham a gravidade que eu vi de certos lugares como, por exemplo, da Casa da Morte de Petrópolis, do DOI-CODI do Rio, do DOI-CODI de São Paulo e outros lugares do Brasil. De qualquer maneira, eu vi uma coisa e tenho curiosidade até hoje de saber. Eu ouvia referências de uma casa onde se torturava e houve até sugestão de que desapareceu gente de lá, uma casa da beira do rio [Rio Paraibuna], do lado do rio, uma coisa assim. Pode ser que tenha havido uma casa junto do rio, não sei se de cá ou de lá, mas uma casa onde aconteciam coisas graves e que até hoje eu não ouvi falar qual era o endereço desta casa, como há em outros estados também, né! (DEPOIMENTOS, 2017, p. 9).

Outro advogado de presos políticos a confirmar os casos de tortura em Juiz de Fora é Winston Jones Paiva, em depoimento à CMV-JF. Conforme o advogado: 
Eu vi casos de tortura, muitas vezes não tortura física, mas tortura psicológica, que às vezes é até pior do que a tortura física, como o caso do Avelino Coque Torres que foi encapuzado, colocado nu em um lugar refrigerado e ameaçando levar a família dele para Ilha Grande. Então, essas ameaças assim aconteceram muito, e eu posso dar esses dois exemplos pra vocês entenderem que, de fato, houve tortura. Ninguém pode negar que houve tortura. [...] Me parece, eu não tenho certeza, mas me parece que o Avelino foi para o QG, Quartel General. Aqui eram três lugares, o QG, era o $10^{\circ} \mathrm{BI}, 10^{\mathrm{a}}$ Brigada de Infantaria e a Penitenciária Edson Cavalieri (DEPOIMENTOS, 2017, p. 3).

O professor e dramaturgo José Luiz Ribeiro, na década de 1960, trabalhava como jornalista no jornal Diário Mercantil e relatou, em seu depoimento à CMV-JF, que:

A gente sabia o que estava acontecendo, xingava e tudo, né, mas na hora de escrever tinha um editor. [...] Esse processo, então, se conseguia modificar porque as coisas aconteciam porque Juiz de Fora recebeu os presos políticos; eles eram julgados aqui, então, muita coisa acontecia, muitos companheiros foram presos (DEPOIMENTOS, 2017 p. 3).

Dessa forma, ainda não nos foi possível confirmar de modo satisfatório a veracidade das informações sobre casos de tortura ocorridos em Juiz de Fora, pois, por enquanto, só temos relatos de pessoas envolvidas diretamente com o processo repressor.

Outro profissional da imprensa a falar sobre o período é o jornalista Paulo César Magella que esclarece, em seu depoimento à CMV-JF, algumas questões a respeito da censura e da autocensura, pois se havia o trabalho da repressão e o medo, havia também o interesse financeiro das empresas de comunicação:

É bom entender que nós estávamos em uma conjuntura de medo naquela época. Era uma autocensura? Era, mas as pessoas andavam com o freio de mão puxado, digamos assim. Mas com o governo Geisel, com essa descompressão, as pessoas começaram a ter um pouco mais de ousadia. Havia muito medo também de perder a concessão. Mas o jornal já começou a avançar. [...] E aí você tinha que fazer uma cobertura, as rádios tinham que fazer quase que obrigadas. 7 de setembro tinha que transmitir. 
E na véspera você tinha que ir ao quartel pegar a ordem dos desfiles, tinha que ficar no palanque, "passa agora a tropa tal"... Era um negócio assim muito pressionado. [...] Medo e até mesmo interesse, naquele tempo, de ficar... massa publicitária... pressão. Não vamos também falar que não éramos... Os jornais também não eram tão resistentes. Muitos não eram resistentes. Muitos participavam também, sabiam o que estava acontecendo e foi feita a cobertura. [...] Os jornais, ainda mais do interior, onde havia uma pressão muito grande econômica. Se você não fizesse uma cobertura adequada, você teria retaliações (DEPOIMENTOS, 2017, p. 6).

Dessa forma, ao analisarmos os poderes discursivos (FOUCAULT, 2007) da imprensa, dos documentos oficiais e dos jornais clandestinos foi-nos possível perceber como se conduz a vontade de verdade em nossa sociedade, pois a forma como o saber legal e legítimo é produzido, aplicado, valorizado e atribuído, permite que se exerça poder de coerção sobre outros discursos, considerada ilegal e ilegítima, interditando-lhes a palavra e conjurando-lhes a eficácia e a ameaça, cujo intuito é ocultar as forças que materializam a constituição social, haja vista que o discurso não reflete apenas o controle do poder, mas é, igualmente, o próprio poder.

Assim sendo, é preciso que se deixe bem claro que não é que os profissionais da imprensa não soubessem ou fossem censurados pelo sistema repressivo instituído a partir de 1964, mas que muitos profissionais se calaram, por medo ou por apoiarem a ditadura, diante das incisivas revelações, enquanto outros foram coniventes com os crimes cometidos. Fica-nos claro, consequentemente, que o silenciamento, mesmo após décadas do acontecido, e, em alguns casos, a adesão foram a marca característica da imprensa durante a ditadura civil-militar de 1964 no Brasil. 


\section{Referências}

BARBOSA, M. História da comunicação no Brasil. Petrópolis: Vozes, 2013.

BIERRENBACH, J. S. Depoimento. 07/06/2006. Rio de Janeiro, CPDOC/SUPERIOR TRIBUNAL MILITAR, 2010. 14p. Disponível em: http://www.fgv.br/cpdoc/historal/ arq/Entrevista1522.pdf. Acesso em: 8 maio 2018.

CMV-JF. Comissão Municipal da Verdade. Disponível em: www.ufjf.br/comissaodaverdade/2016/09/21/livro-da-comissao-municipal-da-verdade-ganha-segunda-edicao.

Acesso em: 30 nov. 2017.

DEPOIMENTOS. Depoimentos à Comissão Municipal da Verdade de Juiz de Fora. Disponível em: www.ufjf.br/comissaodaverdade/depoimentos. Acesso em: 30 maio 2017. DERRIDA, J. Mal de arquivo - uma impressão freudiana. Rio de Janeiro: Relume-Dumará, 2001.

DIÁRIO MERCANTIL. Setor de Memória da Biblioteca Municipal Murilo Mendes. Juiz de Fora, Minas Gerais.

FOUCAULT, M. A arqueologia do saber. Rio de Janeiro: Forense Universitária, 2008.

FOUCAULT, M. A ordem do discurso. São Paulo: Loyola, 2007.

FOUCAULT, M. A verdade e as formas jurídicas. Rio de Janeiro: NAU, 2003.

FOUCAULT, M. Em defesa da sociedade. São Paulo: Martins Fontes, 1999.

FOUCAULT, M. Qu'est-ce que la critique? Critique et Aufklärung. Bulletin de la Société Française de Philosophie, v. 82, n. 2, p. 35-63, avr/juin, 1990. Disponível em: http:// portalgens.com.br/portal/images/stories/pdf/critica.pdf. Acesso em: 3 abr. 2018.

FRONZA, D. Inquérito Policial Militar. Disponível em: http://www.direitonet.com.br/ artigos/x/30/99/3099/. Acesso em: 8 jun. 2017.

PROCESSO 73/69. Auditoria da $4^{\mathrm{a}}$ CJM - STM.

PROCESSO 32/70. Auditoria da $4^{\text {a }}$ CJM - STM.

\section{Sobre os autores}

Ramsés Albertoni Barbosa - Professor de Literatura. Mestre em Poética pela UFRJ. Mestrando em Comunicação pelo PPGCOM-UFJF. No presente artigo, o autor atuou na pesquisa dos arquivos, na interpretação dos dados recolhidos, na revisão bibliográfica e na redação do texto.

Christina Ferraz Musse - Mestre em Comunicação e Cultura pela Universidade Federal do Rio de Janeiro (2001) e doutora em Comunicação e Cultura pela Universidade Federal do Rio de Janeiro (2006). Professora/Coordenadora 
do PPGCOM-UfJF e líder do Grupo de Pesquisa COMCIME. No presente artigo, a autora atuou na concepção do desenho da pesquisa e desenvolvimento da discussão teórica.

Data de submissão: 24/04/2019

Data de aceite: 22/09/2019 